\title{
Impact of the Ligand Flexibility and Solvent on the O-O Bond Formation Step in a Highly Active Ruthenium Water Oxidation Catalyst
}

\author{
Nitish Govindarajan, ${ }^{\circledR}$ Ambuj Tiwari, Bernd Ensing, ${ }^{\circledR}$ and Evert Jan Meijer*우 \\ Amsterdam Center for Multiscale Modeling and Van't Hoff Institute for Molecular Sciences, University of Amsterdam, Science Park \\ 904, 1098XH Amsterdam, The Netherlands
}

\section{Supporting Information}

ABSTRACT: By advanced molecular dynamics simulations, we show that for a highly active ruthenium-based water oxidation catalyst the dangling carboxylate group of the catalyst plays an important role in the crucial $\mathrm{O}-\mathrm{O}$ bond formation step. The interplay of the flexible group and solvent molecules facilitates two possible pathways: a direct pathway with a single solvent water molecule or a mediated pathway involving two solvent water molecules, which have similar activation barriers. Our results provide an example for which a realistic molecular dynamics approach, incorporating an explicit description of the solvent, is required to reveal the full complexity of an important catalytic reaction in aqueous solvent.

$\mathrm{W}$ ith a substantial growth in worldwide energy demand, there is a strong urgency in identifying affordable, renewable, and clean energy sources. Sunlight-driven water splitting to produce molecular hydrogen holds promise as an alternative for fossil fuels. The overall water splitting process consists of two subreactions: the oxygen evolution reaction $\left(\mathrm{OER} ; 2 \mathrm{H}_{2} \mathrm{O} \rightarrow 4 \mathrm{H}^{+}+4 \mathrm{e}^{-}+\mathrm{O}_{2}\right.$ ) and a proton reduction reaction $\left(4 \mathrm{H}^{+}+4 \mathrm{e}^{-} \rightarrow 2 \mathrm{H}_{2}\right)$. The OER is considered to be the current bottleneck of this process because of a high overpotential, thereby hindering economically viable applications. Therefore, an important step to help artificial photosynthesis compete with fossil fuels lies in the development of highly efficient, abundant, and stable water oxidation catalysts (WOCs).

Among homogeneous catalysts, a number of highly effective ruthenium-based molecular catalysts have been synthesized ${ }^{1,2}$ since their discovery by Gersten et al. ${ }^{3}$ While most of these catalysts contain multiple metal centers, ${ }^{4,5}$ a number of mononuclear catalysts have also been reported. ${ }^{6-8}$ Two general types of mechanisms have been proposed for formation of the $\mathrm{O}-\mathrm{O}$ bond during the $\mathrm{OER}$ by these catalysts. In one mechanism, this key step involves an $\mathrm{O}-\mathrm{O}$ radical coupling of two ruthenium-oxo radicals (I2M). ${ }^{9}$ The other mechanism involves water nucleophilic attack (WNA) by a water molecule on a high-valent ruthenium-oxo species. In the context of the WNA mechanism, a new family of $\left[\mathrm{Ru}(\mathrm{tda})(\mathrm{py})_{2}\right]^{m+}(m=0-2)$ type catalysts, recently reported by Matheu and co-workers, ${ }^{10}$ is of particular interest. One such catalyst, $\left[\mathrm{Ru}^{\mathrm{IV}}(\mathrm{OH})(\mathrm{tda}-\kappa\right.$ $\left.\left.\mathrm{N}^{3} \mathrm{O}\right)(\mathrm{py})_{2}\right]^{+}(1+)$, exhibits a remarkably high turnover frequency of $8000 \mathrm{~s}^{-1}$ at $\mathrm{pH} 7.0$ (Figure 1). They attribute this high efficiency to easy access of high oxidation states provided by
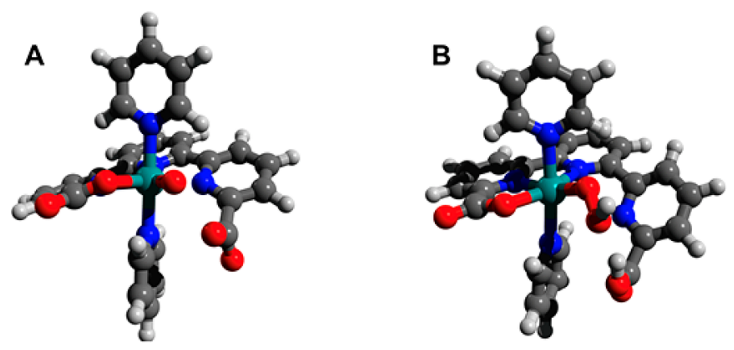

Figure 1. Reactant $1+(\mathrm{A})\left[\mathrm{Ru}^{\mathrm{V}}\left(\mathrm{tda}-\kappa-\mathrm{N}^{3} \mathrm{O}\right)(\mathrm{py})_{2} \mathrm{O}\right]^{+}$(doublet) and product $(\mathrm{B})\left[\mathrm{Ru}^{\mathrm{III}}(\mathrm{OOH})\left(\mathrm{Htda}-\kappa-\mathrm{N}^{3} \mathrm{O}\right)(\mathrm{py})_{2}\right]^{+}$(doublet) structures of the WNA step.

the $\mathrm{tda}^{2-}$ ligand and the presence of a dangling carboxylate group, which facilitates an intramolecular proton transfer during the crucial WNA step. Such an enhancement of the catalytic activity by the presence of a pendant base to abstract the proton during WNA has also been observed in a number of previous studies. $^{11,12}$

An accurate molecular understanding of the key WNA step is essential in identifying crucial structure-activity relationships that can help in the rational catalyst design of such highly efficient WOCs. In this context, molecular modeling can provide important novel insights that are complementary to experimental studies. Previous work on similar systems has emphasized the importance of an explicit solvent description for accurate predictions of the reaction mechanisms and activation barriers. ${ }^{13-15}$ Additionally, some recent modeling studies of cobalt- and iron-based molecular catalysts for water oxidation have incorporated an explicit solvent for a detailed understanding of the reaction mechanism. ${ }^{16-18}$

Here, we report a density functional theory (DFT)-based molecular dynamics (MD) study of the WNA step of complex $1+$, incorporating a realistic explicit solvent description in full molecular detail. This allows us to gain quantitative insight on the intramolecular proton-transfer mechanism during the $\mathrm{O}-\mathrm{O}$ bond formation. We used constrained dynamics ${ }^{19,20}$ to sample, in a controlled manner, the $\mathrm{O}-\mathrm{O}$ bond formation and protontransfer steps. This allowed us to determine the reaction mechanism and associated free-energy profiles. Calculations were performed with the $C P 2 \mathrm{~K}$ package. ${ }^{21}$ The model consisted of the ruthenium catalyst with 93 explicit water molecules in a

Received: March 8, 2018

Published: May 7, 2018 
cubic periodic system $(L=15 \AA)$, ensuring at least two solvation shells around the reactive region. The temperature is controlled by a thermostat set to $350 \mathrm{~K}^{22}$ The electronic structure was determined using the BLYP functional, ${ }^{23,24}$ supplemented with a dispersion correction. ${ }^{25}$ We use the method of constraints to control the $\mathrm{O}-\mathrm{O}$ bond formation and determine the associated free-energy profile along the reaction pathways.

An important first observation in a $60 \mathrm{ps}$ (ps) production run of the reactant $(\mathrm{A})$ in aqueous solution is that the dangling carboxylate group shows a large extent of flexibility, as quantified in Figure 2. An important consequence is that, for smaller $\mathrm{O}_{\mathrm{Ru}}-$

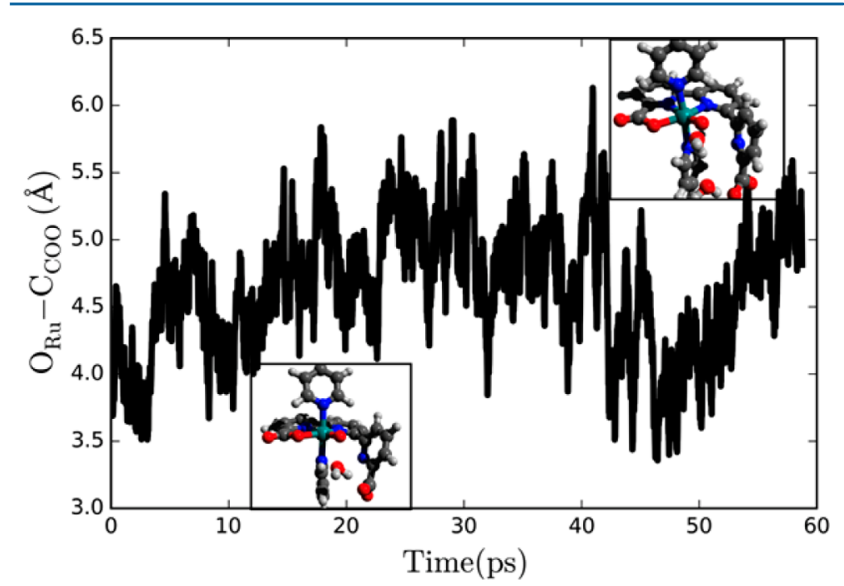

Figure 2. Calculated distances between the $\mathrm{Ru}-\mathrm{O}$ moiety $\left(\mathrm{O}_{\mathrm{Ru}}\right)$ and the carbon of the carboxylate group $\left(\mathrm{C}_{\mathrm{COO}}\right)$ during the production run. The flexibility of the dangling carboxylate group allows for the bridging by one and two water molecules.

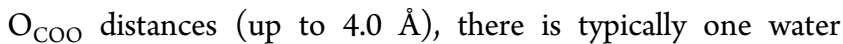
molecule that could attack the $\mathrm{Ru}-\mathrm{O}$ moiety, while transferring a proton directly to the carboxylate oxygen. For larger distances, a significant part of the trajectory shows two water molecules near the $\mathrm{Ru}-\mathrm{O}$ moiety, which allows for the possibility of a $\mathrm{O}-\mathrm{O}$ bond formation accompanied by a water-mediated proton transfer to the carboxylate oxygen. We have not observed configurations with three intermediate water molecules. From a quantitative analysis of the $60 \mathrm{ps}$ trajectory of the solvated reactant, in combination with additional constrained dynamics calculations (see the Supporting Information), we estimate that the range of $\mathrm{O}_{\mathrm{Ru}}-\mathrm{O}_{\mathrm{COO}}$ distances up to $4.0 \AA$ (mostly configurations with one intermediate water molecule) is 1020 times less probable than the range of longer $\mathrm{O}_{\mathrm{Ru}}-\mathrm{O}_{\mathrm{COO}}$ distances (mostly configurations with two intermediate water molecules). This corresponds to a free-energy difference of $1-2$ $\mathrm{kcal} \mathrm{mol}^{-1}$.

Although the simulations of the solvated compound suggest that configurations with two intermediate water molecules are more frequent than those with one water molecule, the associated free-energy difference is relatively small. We therefore consider it useful to estimate the competition between these different mechanisms, also because the latter had already been proposed by Matheu and co-workers. ${ }^{10}$ We performed constrained dynamics with the $\mathrm{O}-\mathrm{O}$ bond distance as the reaction coordinate $(\mathrm{Q})$, to estimate their respective activation barriers. For both mechanisms, we observed the proton transfer to occur spontaneously and reversibly when the $\mathrm{O}-\mathrm{O}$ distance is reduced to $1.8 \AA$. This suggests that, with the chosen imposed reaction coordinate, the relevant configurations along the entire reaction pathway are properly sampled. Additionally, this reaction coordinate has been successfully used in previous studies on the WNA step. ${ }^{17,26}$

The activation barriers for both of these mechanisms are similar, 11.7 and $11.6 \mathrm{kcal} \mathrm{mol}^{-1}$, respectively, as shown in Figure 3. The relative stabilities of the two states are also of the same

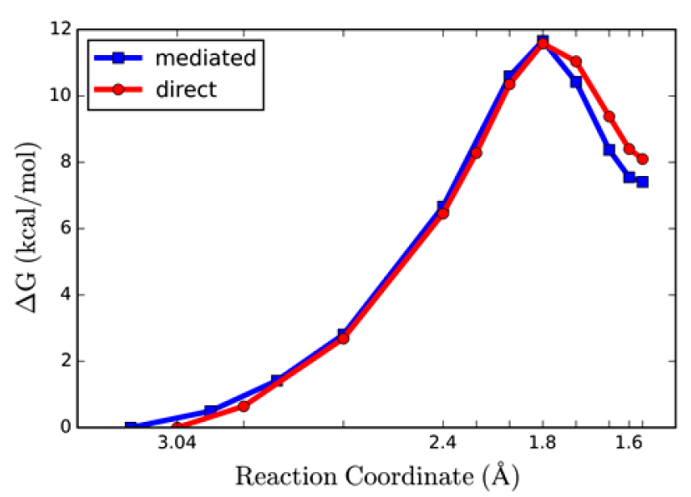

Figure 3. Free-energy profiles for the direct (Mech-1) and mediated (Mech-2) mechanisms in solution.

magnitude $\left(7.4\right.$ and $\left.8 \mathrm{kcal} \mathrm{mol}^{-1}\right)$. This indicates that both of these mechanisms could occur. A comparable barrier makes sense for both mechanisms because they are similar: the mediating water molecule acts as a proton relay to assist in proton transfer to the acceptor base, which is the dangling carboxylate group in this case. Such water-mediated mechanisms have been observed earlier in modeling studies ${ }^{27-29}$ and are a manifestation of the Grotthus mechanism. ${ }^{30}$ The observation that, in the MD trajectory of the reactant, most of the configurations favored the possibility of a mediated mechanism (Figure 2) is an indication that this mechanism is more likely in an aqueous solvent. Further study and analysis of dynamical reaction pathways, using, e.g., transition path sampling, ${ }^{31}$ are required to quantify the kinetic aspects of the $\mathrm{O}-\mathrm{O}$ bond formation WNA step.

Llobet and co-workers report the activation barrier to be 16.8 $\mathrm{kcal} \mathrm{mol}^{-1}$ using a (different) meta-GGA functional in the gas phase, with corrections using the implicit solvation model. ${ }^{10}$ Here we should note that a substantial part of the discrepancy may have its origin in the use of different functionals (see the Supporting Information).

Representative snapshots of configurations from the constrained dynamics simulations for the investigated mechanisms are shown in Figure 4. At an $\mathrm{O}-\mathrm{O}$ distance of $1.80 \AA$, in the case of the mediated mechanism, we see that the proton is transferred back and forth between the attacking water and the carboxylate group. Figure 4A shows an example configuration where the mediating water molecule exists as a hydronium ion $\left(\mathrm{H}_{3} \mathrm{O}^{+}\right)$ stabilized by hydrogen bonds with surrounding water molecules for a few femtoseconds, before transferring the proton to the carboxylate group. At an $\mathrm{O}-\mathrm{O}$ distance of $1.80 \AA$ for the direct mechanism (Figure $4 \mathrm{~B}$ ), the proton is also transferred back and forth. It appears that the transition states occur at the same reaction coordinate distance for both mechanisms and, unlike the study by Hynes and co-workers, ${ }^{32}$ the mediating water molecule does not seem to lower the activation barrier, but acts as a relay to facilitate proton transfer to the dangling carboxylate ligand.

To conclude, we have studied the WNA step of a highly active ruthenium-based catalyst in explicit solvent using DFT-based MD. We find the dangling carboxylate group of the catalyst to show a high degree of flexibility in solution, allowing for two 


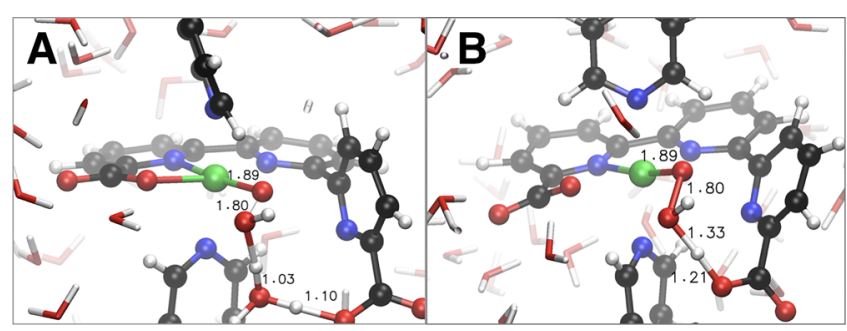

Figure 4. Representative snapshots selected from the MD trajectories (distances shown in angstroms). (A) Transition-state structure for the mediated mechanism, just before $\mathrm{O}-\mathrm{O}$ bond formation. Here, the attacking water molecule has transferred a proton to the second water molecule, which exists as a hydronium ion $\left(\mathrm{H}_{3} \mathrm{O}^{+}\right)$for a few femtoseconds ( $\mathrm{fs}$ ), before transferring a proton to the carboxylate group. (B) Transition-state structure for the direct mechanism, just before the $\mathrm{O}-\mathrm{O}$ bond formation. Here, with the attacking water approaching the oxo moiety, the proton is simultaneously transferred to the carboxylate group.

possible mechanisms during the WNA step. Using advanced biased sampling techniques, we provide a strong indication that these are competing mechanisms because they have the same activation barriers. As the simulations show that configurations with two intermediate water molecules are more likely by a factor in the range of 10-20, the water-mediated mechanism might be the dominant process in an aqueous solution.

The flexibility has been recognized as a potential important characteristic of WOCs. ${ }^{33,34}$ For example, it has been suggested as the main factor to switch from a WNA-type mechanism to the radical coupling mechanism. ${ }^{34}$ The present work provides an important novel result and insight into another aspect of flexibility: we show in explicit molecular detail, on a quantitative level of accuracy, how the thermal motion of a flexible ligand leads to multiple distinct reaction pathways that are mediated by different solvent structures. In a broader context, our results demonstrate that a realistic modeling approach, incorporating a molecular description of solvent- and temperature-induced fluctuations, can be essential to reveal the full complexity of catalytic reactions in an aqueous solvent. We anticipate that using this approach will be of significant importance in the rational design and synthesis of efficient WOCs.

\section{ASSOCIATED CONTENT}

\section{S Supporting Information}

The Supporting Information is available free of charge on the ACS Publications website at DOI: 10.1021/acs.inorgchem.8b00619.

Video 1. A movie of the transition state trajectory from the constrained $\mathrm{MD}$ simulations for the direct mechanism (Mech-1) at the O-O distance of 1.8 A (AVI)

Video 2. A movie of the transition state trajectory from the constrained MD simulations for the mediated mechanism (Mech-2) at the O-O distance of $1.8 \mathrm{~A}$ (AVI)

Details on electronic structure and MD calculations (PDF)

\section{AUTHOR INFORMATION}

\section{Corresponding Author}

*E-mail: e.j.meijer@uva.nl.

ORCID $\odot$

Nitish Govindarajan: 0000-0003-3227-5183

Bernd Ensing: 0000-0002-4913-3571
Evert Jan Meijer: 0000-0002-1093-9009

Notes

The authors declare no competing financial interest.

\section{ACKNOWLEDGMENTS}

This work is part of the Industrial Partnership Program Computational Sciences for Energy Research (Grant 14CSER044), which is financially supported by The Netherlands Organization for Scientific Research (NWO). This research program is cofinanced by Shell Global Solutions International BV.

\section{REFERENCES}

(1) Duan, L.; Wang, L.; Li, F.; Li, F.; Sun, L. Highly Efficient Bioinspired Molecular Ru Water Oxidation Catalysts with Negatively Charged Backbone Ligands. Acc. Chem. Res. 2015, 48 (7), 2084-2096.

(2) Blakemore, J. D.; Crabtree, R. H.; Brudvig, G. W. Molecular Catalysts for Water Oxidation. Chem. Rev. 2015, 115 (23), 1297413005.

(3) Gersten, S. W.; Samuels, G. J.; Meyer, T. J. Catalytic Oxidation of Water by an Oxo-Bridged Ruthenium Dimer. J. Am. Chem. Soc. 1982, 104 (14), 4029-4030.

(4) Kuznetsov, A. E.; Geletii, Y. V.; Hill, C. L.; Morokuma, K.; Musaev, D. G. Dioxygen and Water Activation Processes on Multi-RuSubstituted Polyoxometalates: Comparison with the "Blue-Dimer" Water Oxidation Catalyst. J. Am. Chem. Soc. 2009, 131 (19), 68446854.

(5) Neudeck, S.; Maji, S.; López, I.; Meyer, S.; Meyer, F.; Llobet, A. New Powerful and Oxidatively Rugged Dinuclear Ru Water Oxidation Catalyst: Control of Mechanistic Pathways by Tailored Ligand Design. J. Am. Chem. Soc. 2014, 136 (1), 24-27.

(6) Wasylenko, D. J.; Ganesamoorthy, C.; Koivisto, B. D.; Henderson, M. A.; Berlinguette, C. P. Insight into Water Oxidation by Mononuclear Polypyridyl Ru Catalysts. Inorg. Chem. 2010, 49 (5), 2202-2209.

(7) Kaveevivitchai, N.; Zong, R.; Tseng, H.-W.; Chitta, R.; Thummel, R. P. Further Observations on Water Oxidation Catalyzed by Mononuclear Ru(II) Complexes. Inorg. Chem. 2012, 51 (5), 29302939.

(8) Concepcion, J. J.; Jurss, J. W.; Templeton, J. L.; Meyer, T. J. One Site Is Enough. Catalytic Water Oxidation by $[\mathrm{Ru}(\mathrm{tpy})(\mathrm{bpm})(\mathrm{OH} 2)]$ $2+$ and $[\mathrm{Ru}(\mathrm{tpy})(\mathrm{bpz})(\mathrm{OH} 2)] 2+$. J. Am. Chem. Soc. 2008, 130 (49), $16462-16463$.

(9) Duan, L.; Araujo, C. M.; Ahlquist, M. S. G.; Sun, L. Highly Efficient and Robust Molecular Ruthenium Catalysts for Water Oxidation. Proc. Natl. Acad. Sci. U. S. A. 2012, 109 (39), 15584-15588.

(10) Matheu, R.; Ertem, M. Z.; Benet-Buchholz, J.; Coronado, E.; Batista, V. S.; Sala, X.; Llobet, A. Intramolecular Proton Transfer Boosts Water Oxidation Catalyzed by a Ru Complex. J. Am. Chem. Soc. 2015, 137 (33), 10786-10795.

(11) Sala, X.; Ertem, M. Z.; Vigara, L.; Todorova, T. K.; Chen, W.; Rocha, R. C.; Aquilante, F.; Cramer, C. J.; Gagliardi, L.; Llobet, A. The Cis-[RuII(bpy)2(H2O)2]2+ Water-Oxidation Catalyst Revisited. Angew. Chem., Int. Ed. 2010, 49 (42), 7745-7747.

(12) Xie, Y.; Shaffer, D. W.; Lewandowska-Andralojc, A.; Szalda, D. J.; Concepcion, J. J. Water Oxidation by Ruthenium Complexes Incorporating Multifunctional Bipyridyl Diphosphonate Ligands. Angew. Chem., Int. Ed. 2016, 55 (28), 8067-8071.

(13) Ma, C.; Piccinin, S.; Fabris, S. Reaction Mechanisms of Water Splitting and $\mathrm{H} 2$ Evolution by a Ru(II)-Pincer Complex Identified with Ab Initio Metadynamics Simulations. ACS Catal. 2012, 2 (7), 15001506.

(14) Pavlova, A.; Meijer, E. J. Understanding the Role of Water in Aqueous Ruthenium-Catalyzed Transfer Hydrogenation of Ketones. ChemPhysChem 2012, 13 (15), 3492-3496.

(15) Handgraaf, J.-W.; Meijer, E. J. Realistic Modeling of RutheniumCatalyzed Transfer Hydrogenation. J. Am. Chem. Soc. 2007, 129 (11), 3099-3103. 
(16) Hodel, F. H.; Luber, S. What Influences the Water Oxidation Activity of a Bioinspired Molecular CoII4O4 Cubane? An In-Depth Exploration of Catalytic Pathways. ACS Catal. 2016, 6 (3), 1505-1517.

(17) Bernasconi, L.; Kazaryan, A.; Belanzoni, P.; Baerends, E. J. Catalytic Oxidation of Water with High-Spin Iron(IV)-Oxo Species: Role of the Water Solvent. ACS Catal. 2017, 7 (6), 4018-4025.

(18) Mattioli, G.; Giannozzi, P.; Amore Bonapasta, A.; Guidoni, L. Reaction Pathways for Oxygen Evolution Promoted by Cobalt Catalyst. J. Am. Chem. Soc. 2013, 135 (41), 15353-15363.

(19) Carter, E. A.; Ciccotti, G.; Hynes, J. T.; Kapral, R. Constrained Reaction Coordinate Dynamics for the Simulation of Rare Events. Chem. Phys. Lett. 1989, 156 (5), 472-477.

(20) Sprik, M.; Ciccotti, G. Free Energy from Constrained Molecular Dynamics. J. Chem. Phys. 1998, 109 (18), 7737-7744.

(21) VandeVondele, J.; Krack, M.; Mohamed, F.; Parrinello, M.; Chassaing, T.; Hutter, J. Quickstep: Fast and Accurate Density Functional Calculations Using a Mixed Gaussian and Plane Waves Approach. Comput. Phys. Commun. 2005, 167 (2), 103-128.

(22) Bussi, G.; Donadio, D.; Parrinello, M. Canonical Sampling through Velocity Rescaling. J. Chem. Phys. 2007, 126 (1), 14101.

(23) Becke, A. D. Density-Functional Exchange-Energy Approximation with Correct Asymptotic Behavior. Phys. Rev. A: At., Mol., Opt. Phys. 1988, 38 (6), 3098-3100.

(24) Lee, C.; Yang, W.; Parr, R. G. Development of the Colle-Salvetti Correlation-Energy Formula into a Functional of the Electron Density. Phys. Rev. B: Condens. Matter Mater. Phys. 1988, 37 (2), 785-789.

(25) Grimme, S.; Antony, J.; Ehrlich, S.; Krieg, H. A Consistent and Accurate Ab Initio Parametrization of Density Functional Dispersion Correction (DFT-D) for the 94 Elements H-Pu. J. Chem. Phys. 2010, 132 (15), 154104.

(26) Vallés-Pardo, J. L.; Guijt, M. C.; Iannuzzi, M.; Joya, K. S.; de Groot, H. J. M.; Buda, F. Ab Initio Molecular Dynamics Study of Water Oxidation Reaction Pathways in Mono-Ru Catalysts. ChemPhysChem 2012, 13 (1), 140-146.

(27) Pavlova, A.; Trinh, T. T.; van Santen, R. A.; Meijer, E. J. Clarifying the Role of Sodium in the Silica Oligomerization Reaction. Phys. Chem. Chem. Phys. 2013, 15 (4), 1123-1129.

(28) Trinh, T. T.; Jansen, A. P. J.; van Santen, R. A.; Jan Meijer, E. The Role of Water in Silicate Oligomerization Reaction. Phys. Chem. Chem. Phys. 2009, 11 (25), 5092-5099.

(29) Wang, L.; Yu, X.; Hu, P.; Broyde, S.; Zhang, Y. A Water-Mediated and Substrate-Assisted Catalytic Mechanism for Sulfolobus Solfataricus DNA Polymerase IV. J. Am. Chem. Soc. 2007, 129 (15), 4731-4737.

(30) Marx, D. Proton Transfer 200 Years after von Grotthuss: Insights from Ab Initio Simulations. ChemPhysChem 2006, 7 (9), 1848-1870.

(31) Bolhuis, P. G.; Chandler, D.; Dellago, C.; Geissler, P. L. Transition Path Sampling: Throwing Ropes Over Rough Mountain Passes, in the Dark. Annu. Rev. Phys. Chem. 2002, 53 (1), 291-318.

(32) Bianco, R.; Hay, P. J.; Hynes, J. T. Proton Relay and Electron Flow in the O-O Single Bond Formation in Water Oxidation by the Ruthenium Blue Dimer. Energy Environ. Sci. 2012, 5 (7), 7741-7746.

(33) Hodel, F. H.; Luber, S. Redox-Inert Cations Enhancing Water Oxidation Activity: The Crucial Role of Flexibility. ACS Catal. 2016, 6 (10), 6750-6761.

(34) Tong, L.; Duan, L.; Xu, Y.; Privalov, T.; Sun, L. Structural Modifications of Mononuclear Ruthenium Complexes: A Combined Experimental and Theoretical Study on the Kinetics of RutheniumCatalyzed Water Oxidation. Angew. Chem., Int. Ed. 2011, 50 (2), 445449. 